\title{
Prosthetic-free ribs stabilization technique in critical complex chest wall traumas: first results and experiences
}

\author{
Paolo N. C. Girotti^, Peter Tschann, Ingmar Königsrainer \\ Department of General, Visceral and Thoracic Surgery, Landeskrankenhaus Feldkirch, Feldkirch, Austria \\ Contributions: (I) Conception and design: All authors; (II) Administrative support: All authors; (III) Provision of study materials or patients: All \\ authors; (IV) Collection and assembly of data: All authors; (V) Data analysis and interpretation: PNC Girotti; (VI) Manuscript writing: All authors; \\ (VII) Final approval of manuscript: All authors. \\ Correspondence to: Paolo N. C. Girotti. Carinagasse 47, 6807 Feldkirch, Austria. Email: paolo.girotti@vlkh.net.
}

\begin{abstract}
Background: Surgical stabilization in complex chest wall traumas, especially in case of posterior ribs arch destruction and flail chest, still remains a challenge for thoracic and trauma surgeons. Throughout the years different techniques and materials developed to address the complex anatomy of the ribs and reach an adequate fixation. Our aim is to present a prosthetic-free ribs stabilization technique which is easily reproducible and can achieve an efficient mechanical stabilization of the chest wall.

Methods: This surgical technique can be summarized in three steps: muscle sparing thoracotomy following modified "Shaw-Paulson's" technique (complete section of the latissimus dorsi muscle along the transverse processes of vertebral spine to rich the serratus muscles plane), prosthetic-free ribs fixation with single stiches $\left(\right.$ Maxon $\left.^{\mathrm{TM}} 1\right)$ and muscles repositioning.

Results: Between January 2018 and June 2020, we retrospectively evaluated ten consecutive patients (six male and four female) which underwent a chest wall stabilization because of a posterior ribs destruction and flail chest. No chest wall deformities were observed during follow-up with CT-scan after 4, 30 and 90 days and no patient underwent additional early or late stabilization procedures.

Conclusions: In the case of severe thoracic trauma with chest wall destruction and flail chest, modified "Shaw-Paulson approach" and prosthetic-free fixation technique with Maxon thread should be considered as a valuable option allowing an adequate stabilization of the chest with optimal respiratory function.
\end{abstract}

Keywords: Trauma; chest wall; prosthesis; surgery

Submitted Jan 17, 2021. Accepted for publication Mar 05, 2021.

doi: $10.21037 /$ jtd-21-111

View this article at: http://dx.doi.org/10.21037/jtd-21-111

\section{Introduction}

Surgical stabilization after complex chest wall traumas, especially in case of flail chest and critical respiratory conditions, still remains a challenge for thoracic and trauma surgeons (1-7). An early definitive ribs stabilization is mandatory to significantly reduce early and late respiratory complications (4-6). The timing when to perform a surgical stabilization is not precisely defined, however, it should be performed within the first 72 hours of injury shortening the intensive care unit (ICU) stay, the number of ventilator days and the days under continuous intravenous narcotic medicaments (2,7-12). Throughout the years different techniques and materials for surgical fixation have appeared such us metal and absorbable bioprosthetic materials. Absorbable materials seem to have mechanical and clinical advantages compared to metal (easier to customize, no need to remove the prosthesis, stimulation of new bone

$\wedge$ ORCID: 0000-0002-0554-5865. 
formation). However, up to now, titanium bars still remain the most commonly used prosthesis $(2,4,8,13-15)$. Our aim is to present, in accordance with the STROBE reporting checklist, a prosthetic-free ribs stabilization technique which doesn't require prosthetic material, is easily reproducible and can achieve an efficient mechanical stabilization also in the case of a complex chest wall destruction with associated flail chest.

We present the following article in accordance with the STROBE reporting checklist (available at http://dx.doi. org/10.21037/jtd-21-111).

\section{Methods}

Patients who met at least two or more of the following criteria on the time of the admission were eligible for the surgical treatment and ribs stabilization:

* more than 5 ribs displaced fractures associated with respiratory failure requiring mechanical ventilation;

* bilateral rib fractures;

* flail chest;

* hemothorax;

* impalement of ribs into pulmonary parenchyma;

* complex diaphragm rupture with hernia.

Hemodynamically and respiratory stable patients underwent a preoperative CT scan with 3-dimensional reconstruction to exactly localize the fractures and to plan the optimal surgical approach and type of reconstruction. Operative treatment of thoracic injury was performed in all patients within 72 hours of trauma.

Analyzed variables in all patients were:

* Demographic and preoperative data: age and sex, trauma mechanism, intubation on the admission, medial number of rib fractures on the flail chests side, side of trauma, number of patients with two or more associated injury.

* -Surgical and postoperative data: median ICU, median total hospital stay, pain-score [visual analog score (VAS)] at second, fourth and seventh postoperative day, median intubations days, total number of patients underwent isolated chest wall stabilization, total number of patients underwent an associated lungs resection and/or laparotomy, median number of ribs fixation, total number of patients underwent scapula fixation, complications (according to Dindo-Clavien classification).

* Follow-up data: not earlier than 4 days after surgery and before removing the last placed pleura drain.
All patients received a total body CT-scan follow-up with contrast medium on the seventh, thirtieth and ninetieth days after the surgery to evaluate the end lung volume, the chest wall symmetry and residual parenchymal lesions. Thereafter the chest volume difference was calculated ( $\Delta=$ total lung volume after ribs stabilization - total lung volume before surgery). A spirometry with plethysmography three month after the discharge was standardly planned.

The study was conducted in accordance with the Declaration of Helsinki (as revised in 2013). The study was approved by regional ethics board of Vorarlberg and individual consent for this retrospective analysis was waived.

This is a retrospective study with one single group and no statistical analysis was conducted.

\section{Surgical technique}

\section{Step 1: muscle sparing thoracotomy following modified} "Shaw-Paulson's" technique

This was the first surgical approach described by Shaw and Paulson (Figure 1). The incision extends around the tip of the scapula and reaches midway between the posterior edge of the scapula and the spinous processes, up to the level of C7 (Figure 1A). Identification of the trapezius and levator scapula muscles (Figure 1B). Almost complete mobilization of the trapezius and the latissimus dorsi muscle along the transverse processes of vertebral spine to rich the serratus muscles plane (Figure 1C). Complete section of the anterior serratus muscle to allow the complete elevation of the scapula (Figure 1D).

\section{Step 2: ribs fixation}

We stabilize the ribs following the cranial-caudal and posterior-anterior direction. Fractures are fixed due to single sutures with absorbable thread Maxon ${ }^{\mathrm{TM}} 1$ BGS-25 Covidien following our technique as showed in Figure 2. We fix from the second to the eighth ribs. At the end of the fixation, two 28-French pleural drains are placed, one of which is placed in the costophrenic angle.

The technique of rib fixation follows a standardized technique:

The first step consists of overbridging the rib fracture with two loops surrounding the rib on both sides, $5 \mathrm{~cm}$ far from the fractures ends (Figure 2A). Secondly, the thread passes through the loops as a $\mathrm{U}$-suture to the origin of the suture. (Figure 2B). This stitch is done at least three times before pulling the knot, always maintaining the tension of 

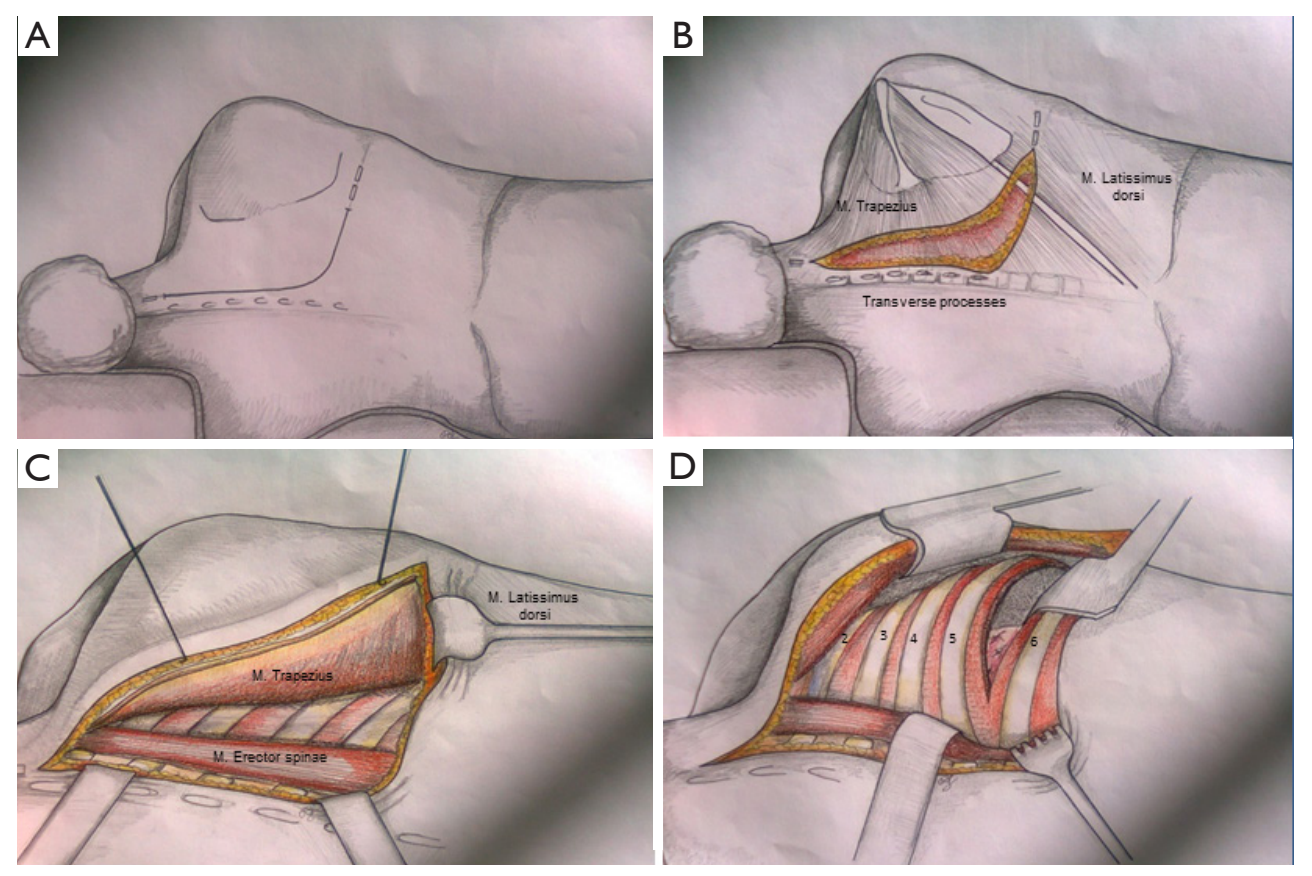

Figure 1 Modified "Shaw-Paulson's" technique. (A) Posterior incision along scapula. (B) Dissection of the root of trapezius and latissimus dorsi muscle. (C) Complete mobilization of the trapezius and the latissimus dorsi muscle. (D) Elevation of the scapula.

the thread during the suture (Figure 2C). Following this technique the fracture is approximated and the two edges of the ribs fit together (Figure 2D).

\section{Step 3: muscle repositioning}

We reposition the dorsalis muscles root along the transverse processes due to a running suture by Prolene $0 \mathrm{~V}-34$ Ethicon. A rubber drain was placed between the chest wall and latissimus dorsi muscle before the dorsalis muscle root reposition.

Subsequently, if a heightened chest wall stability is required after a complete destruction of the first 5 ribs, we fix the scapula by a single stitch with Prolene $0 \mathrm{~V}-34$ (Ethicon) on the posterior arch of the sixth rib (Figure 2D).

\section{Results}

We retrospectively evaluated ten consecutive patients (6 male/4 female) which underwent a chest wall stabilization because of a complex thorax trauma with associated flail chest from 01 January 2018 to 01 June 2020. Preoperative data are shown in Table 1. Median age was 52 years (range:
45-65 years). Most of traumas were vehicle traumas (six patients), 4 patients had sport accidents. Seven patients were intubated on admission, and nine patients had a clinical evident flail chest on first clinical evaluation. Nine patients had more than one associated abdominal or osseous trauma: one patient had a liver and one a spleen injury. These two patients required also an emergency laparotomy: the first patients underwent a left lateral liver resection and the second a splenectomy.

Table 2 shows the postoperative data. Median ICU stay was 6 days (range, 2-15 days). Median hospital stay was 15 days (range, $8-25$ days) and the length of intubation was 2 days (range, $1-4$ days).

All patients required a single unilateral chest wall stabilization. Figures 3,4 show preoperative and postoperative CT-scan and $3 \mathrm{D}$ reconstruction of one patient after vehicle trauma who had right lung hemothorax associated with bilateral multiple ribs fractures and right flail chest. After 24 hours of his admission, the patient underwent a right side thoracotomy: ribs from second to eighth were fixed and an upper-lobe wedge resection was performed due to a parenchymal laceration. 

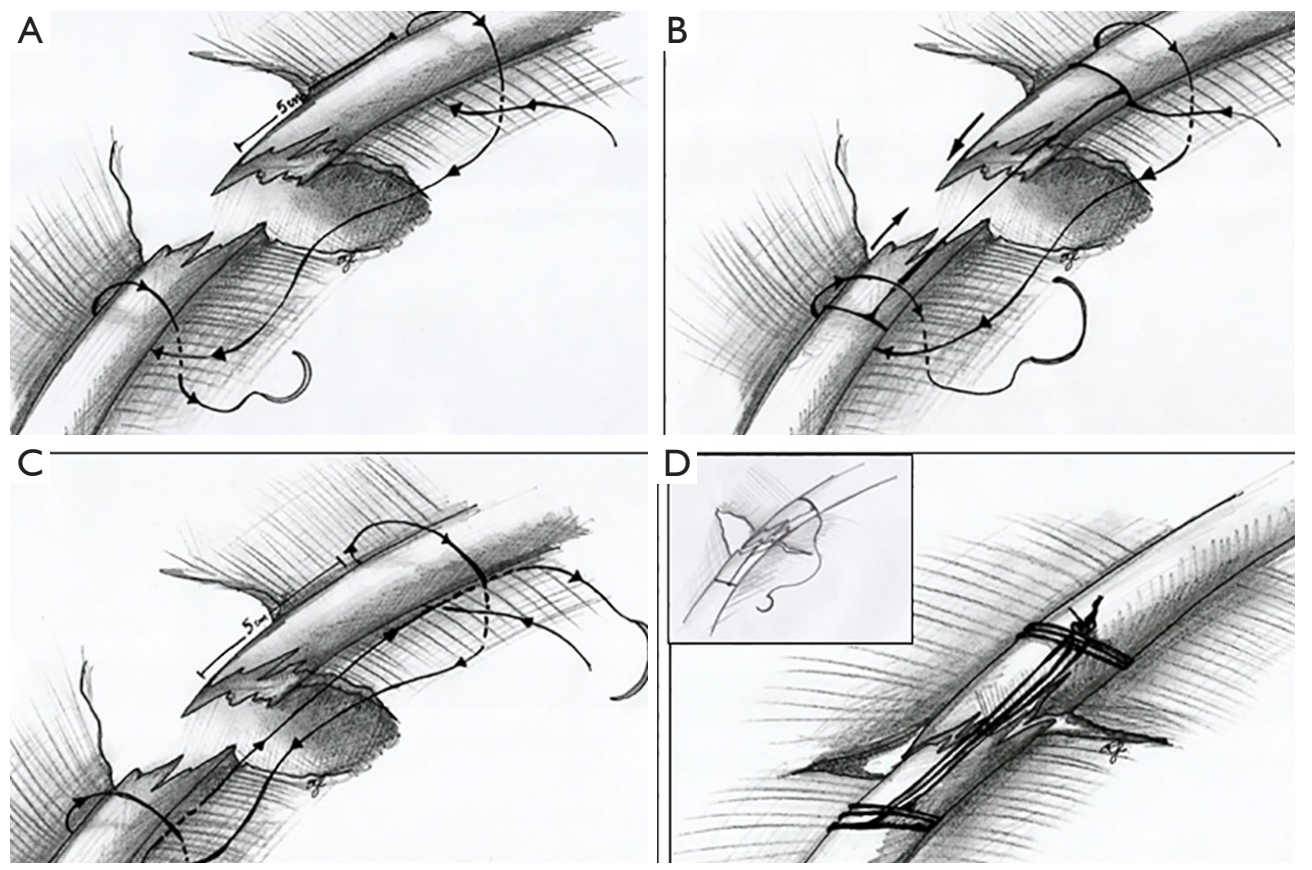

Figure 2 Fixation stitches. (A) Two loops surrounding the rib on both sides. (B) The thread passes through the loops as a U-suture. (C) Three times back and front before pulling the knot. This stitch is done at least three times before pulling the knot, always maintaining the tension of the thread during the suture. (D) Two edges of the ribs fit together.

Table 1 Preoperative and epidemiologic data $(\mathrm{N}=10)$

\begin{tabular}{ll}
\hline Demographic data & Number (range, \%) \\
\hline Sex (male/female) & M: 6 (60\%)/F: 4 (40\%) \\
Median age years [range] & 52 [45-65] \\
Traumas mechanism & $\begin{array}{l}\text { Vehicles: } 6(60 \%) \text { sport: } 4 \\
(40 \%)\end{array}$ \\
$\begin{array}{l}\text { Total number of intubated patients on } \\
\text { the admission }\end{array}$ & 7 (70\%) \\
$\begin{array}{l}\text { Medial number of ribs fractures (side } \\
\text { of the flail chest) }\end{array}$ & 7 [5-12] \\
Side of trauma & Left: $2(20 \%)$ \\
& Right: $3(30 \%)$ \\
& Bilateral: $5(50 \%)$ \\
& Anterior: $2(20 \%)$ \\
Lotal number of patients with $\geq 2$ & Lateral: $2(20 \%)$ \\
associated injuries & Posterior: $1(10 \%)$ \\
\hline
\end{tabular}

Three patients underwent an associated lung resection (non-anatomic resection in two patients and a right upper lobectomy in one patient). In over $90 \%$ of cases, ribs fractures occurred between the second and the sixth. The median number of stabilized ribs was 5.5 (range, 4-7). We observed following postoperative minor complications: two patients developed at fifth and sixth postoperative days pneumonias that required antibiotic therapy. Regarding minor complications (Dindo-Clavien $\geq$ III): one patient developed an intrathoracic hematoma on the second postoperative day. Hematoma was removed by a video-thoracoscopic approach. In another patient a cholecystectomy was required due to an acute cholecystitis which occurred on the fifth postoperative day. No chest wall deformities during a CT-scan follow-up after seven, thirty and ninety days were observed and no patients underwent additional early or late stabilization procedures. Median lost lungs volume $\Delta$ was $5 \%$ on the follow-up CT-scan on seventh day (patient with lobectomy excluded). Only one patient developed pain with a nonunion ribs fracture after 3 months, confirmed in CT scan. Six months after the nonunion region was resected without reconstruction. 
Table 2 Surgical and postoperative data $(\mathrm{n}=10)$

\begin{tabular}{|c|c|}
\hline Clinical data & n (range, \%) \\
\hline Median ICU stay, days [range] & $6[2-15]$ \\
\hline Median hospital stay, days [range] & 15 [8-25] \\
\hline Median length of intubation, days [range] & $2[1-4]$ \\
\hline $\begin{array}{l}\text { Isolated chest wall operation (tot. number of } \\
\text { patients) }\end{array}$ & $5(50 \%)$ \\
\hline $\begin{array}{l}\text { Total number of patients underwent associated } \\
\text { lungs resections }\end{array}$ & $3(30 \%)$ \\
\hline Wedge resection & $2(20 \%)$ \\
\hline Lobectomy & $1(10 \%)$ \\
\hline Associated operations (liver/spleen/bowel) & $\begin{array}{l}2 \text { (20\%; } 1 \text { liver } \\
\text { resection/1 } \\
\text { splenectomy) }\end{array}$ \\
\hline Median number of ribs fixation [range] & $6[4-8]$ \\
\hline $\begin{array}{l}\text { Total number of patients underwent scapula } \\
\text { fixation }\end{array}$ & $3(30 \%)$ \\
\hline \multicolumn{2}{|l|}{ Median pain-score [visual analog score] } \\
\hline Second postoperative day & 5 [2-9] \\
\hline Fourth postoperative day & $4[2-8]$ \\
\hline Seventh postoperative day & $2.5[1-5]$ \\
\hline Tot. n. Patients with complications & $4(40 \%)$ \\
\hline Postoperative complications (Dindo-Clavien) & $\begin{array}{l}\text { I-III: } 2 \text { (50\%); } \\
\text { IV-VI: } 2(50 \%)\end{array}$ \\
\hline $\begin{array}{l}\text { Total number of patients with postoperative } \\
\text { pneumonia }\end{array}$ & $2(20 \%)$ \\
\hline \multirow[t]{3}{*}{ Others complications } & $\begin{array}{l}\text { n. patients: } \\
2(20 \%)\end{array}$ \\
\hline & $\begin{array}{l}1 \text { postoperative } \\
\text { bleeding }\end{array}$ \\
\hline & $\begin{array}{l}1 \text { acute } \\
\text { cholecystitis }\end{array}$ \\
\hline Volume $\Delta$ (median \%) on seventh day & $5 \%$ \\
\hline Volume $\Delta$ (median \%) on thirtieth day & $7.5 \%$ \\
\hline Volume $\Delta$ (median \%) on ninetieth day & $8.1 \%$ \\
\hline Median Postoperative FEV1 after 3 months (\%) & $78 \%$ \\
\hline $\begin{array}{l}\text { Total number of patients with nonunion after } 3 \\
\text { months }\end{array}$ & $1(10 \%)$ \\
\hline
\end{tabular}

Volume $\Delta$, total lung volume after ribs stabilization - total lung volume before surgery.

\section{Discussion}

There is no data in literature which technique of rib stabilization in complex chest traumas should be used $(2,6)$ and in many cases the choice of the technique depends on surgeons' skills and preference.

Operative treatment should be considered in two cases of severe chest wall traumas: flail chest or non-flail chest but with more than 3 severely (bicortical) displaced ribs fractures $(2,6,7,11,12,16)$. Many authors report that patients undergoing ribs stabilization for flail chest have decreased pain, shortened duration of mechanical ventilation, decreased incidence of pneumonia, decreased likelihood of tracheostomy and decreased length of stay in ICU and hospital (2,7,9-12). Furthermore a surgical intervention can be planned if the patient is undergoing a thoracotomy for other indications $(2,7,8)$. As mentioned above there is no consensus about the perfect timing for surgery. However, an early approach, specifically within the first 72 hours, may result in a better outcome and less early and late complications. The ongoing inflammatory process or an initiated callus formation may render the normal alignment of the ribs more difficult causing rigidity with deformity of the chest wall $(2,4,6)$. Most importantly, hemodynamic stability of the patient is mandatory before surgery is taken into consideration (2).

Rib fractures may be categorized in anterior (anterior axillar line), lateral (between anterior axillary line and posterior axillary line) and posterior fractures (posterior axillary line). Depending on their location, different type of operative approaches and incisions are practiced (17). "Shaw-Paulson's" approach permits an optimal exposure of the spine and muscles roots, the apex of the thoracic cage (axillar vascular axis) and allows to explore the thoracic cavity and the lung (18).

Moreover, muscle sparing technique and the muscles root re-insertion at the end of the fixation, without section of the muscles fibers, reduces postoperative pain and is associated with a low rate of early/late postoperative complications, as we report also in our study, even if this surgical approach appears to be very invasive (19).

The best prosthetic material to be used for fixation still remains controversial $(2,6)$. Resorbable material for the fixation seems to avoid the main complications of the prosthetic material itself $(4,10,13-15)$. In intra-medullary fixation for example, there is postoperative risk for wire 

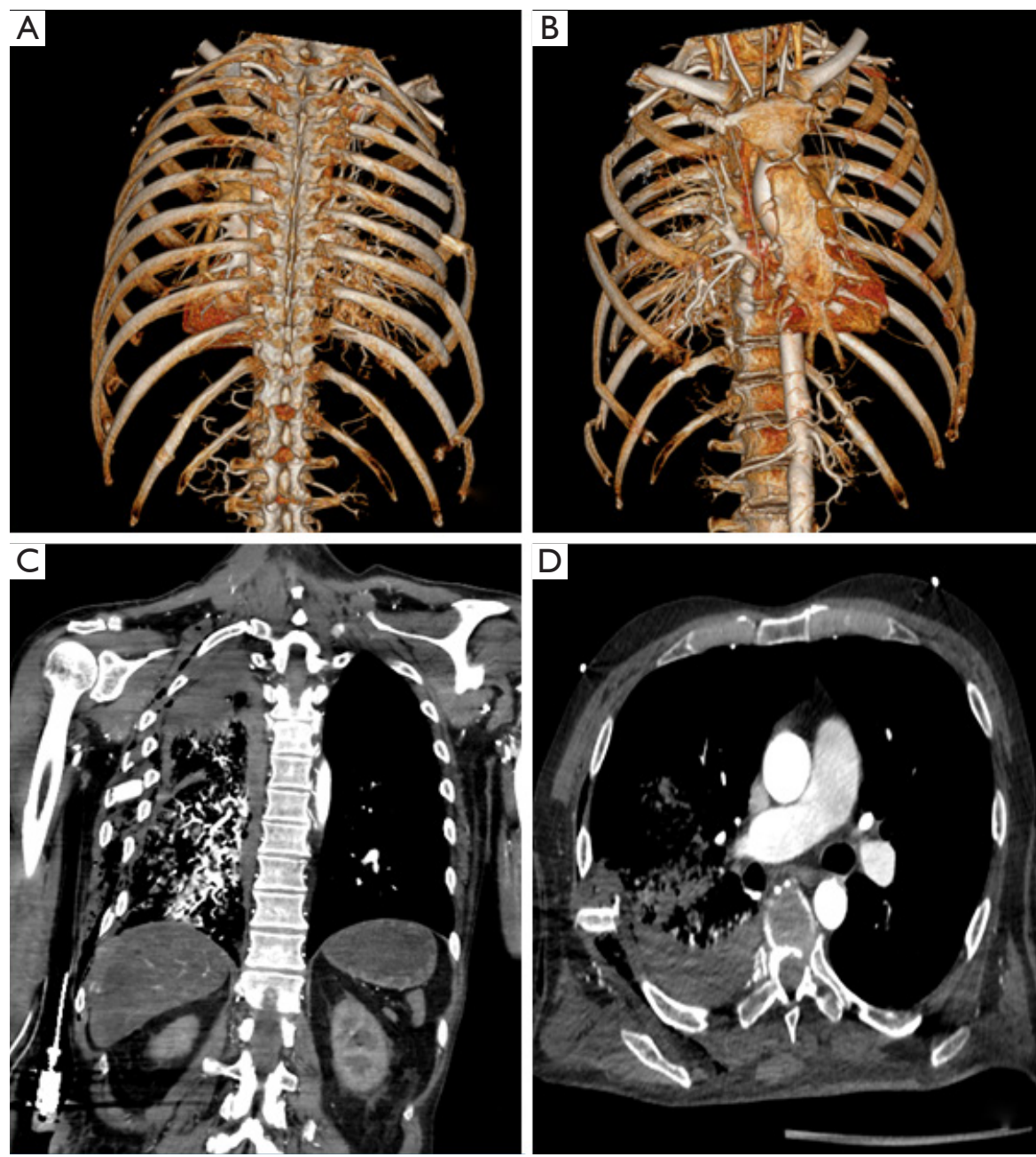

Figure 3 Patient with multiple right-sided rib fractures, flail chest, hemothorax, pneumothorax and subcutaneous emphysema. 3D-reconstruction CT-scan showing the flail chest: (A) posterior view and (B) anterior view. CT-scan showing the multiple complex chest wall destruction: (C) coronal view and (D) transverse view.

dislodgement; moreover, migration through the skin has been reported in animal testing (8). Ribs cerclage may potentially crimp the intercostal neurovascular bundle, which may lead to postoperative and chronic pain $(2,6-8)$ Metal and titanium prosthesis in younger patients, where the process of skeletal growth is still ongoing, are not primarily recommended to be used, also because of a second intervention for prosthetic removal (20).

In addition, ribs do not have the stress tolerance such as other bones and so do not often have the ability to hold cortical screws $(2,10,15)$. All these complications could be avoided simply by utilizing resorbable material. This has shown to allow micro-movement of the fracture line, stimulating osteoclast activity and so callus formation, as well as a gradual force transfer from the stabilization material to the rib which thus enables the stresses and mechanical loads to be gradually transferred to the rib until there is a complete healing of the fracture favouring a more genuine healing of the bone $(10,13,15)$. In addition, the bioprosthetic materials can be easily shaped according to the anatomy of the rib, and can potentially do not impair the elasticity and compliance requirements of the thorax $(8,13)$.

\section{Conclusions}

This study was unavoidably limited by its retrospective nature and by the small sample size. In conclusion, our study shows that in the case of severe thoracic trauma and 

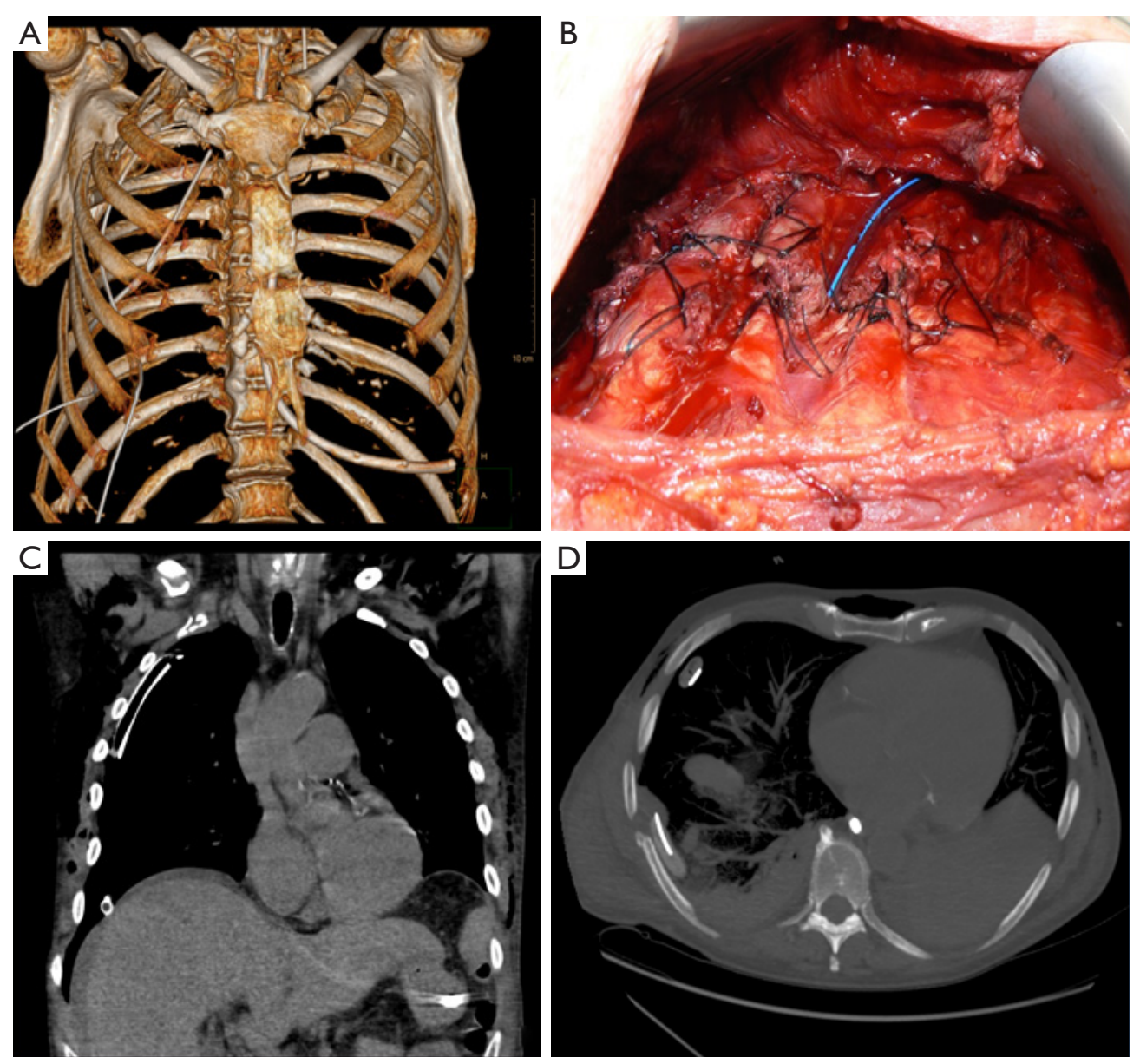

Figure 4 (A) 3D-Reconstruction CT-scan after stabilization (from second to eighth ribs were fixed). (B) Intraoperative picture after stabilization. CT-scan showing the results of the surgical procedure and the restoration of the anatomical ribs curvature: (C) coronal view and (D) transverse view.

chest wall destruction, which resulted in flail chest and respiratory distress, our modified "Shaw-Paulson approach" and prosthetic-free fixation technique should be considered as a valuable option of chest stabilization, with the possibility of simultaneous lung exploration without using prosthetic material.

\section{Acknowledgments}

Funding: None.

\section{Footnote}

Reporting Checklist: The authors have completed the STROBE reporting checklist. Available at http://dx.doi. org/10.21037/jtd-21-111
Data Sharing Statement: Available at http://dx.doi. org/10.21037/jtd-21-111

Peer Review File: Available at http://dx.doi.org/10.21037/jtd21-111

Conflicts of Interest: All authors have completed the ICMJE uniform disclosure form (available at http://dx.doi. org/10.21037/jtd-21-111). The authors have no conflicts of interest to declare.

Ethical Statement: The authors are accountable for all aspects of the work in ensuring that questions related to the accuracy or integrity of any part of the work are appropriately investigated and resolved. The study was conducted in accordance with the Declaration of Helsinki 
(as revised in 2013). The study was approved by regional ethics board of Vorarlberg and individual consent for this retrospective analysis was waived.

Open Access Statement: This is an Open Access article distributed in accordance with the Creative Commons Attribution-NonCommercial-NoDerivs 4.0 International License (CC BY-NC-ND 4.0), which permits the noncommercial replication and distribution of the article with the strict proviso that no changes or edits are made and the original work is properly cited (including links to both the formal publication through the relevant DOI and the license). See: https://creativecommons.org/licenses/by-nc-nd/4.0/.

\section{References}

1. Chien CY, Chen YH, Han ST, et al. The number of displaced rib fractures is more predictive for complications in chest trauma patients. Scand J Trauma Resusc Emerg Med 2017;25:19.

2. Pieracci FM, Majercik S, Ali-Osman F, et al. Consensus statement: surgical stabilization of rib fractures, rib fracture colloquium, clinical practice guidelines. Injury 2017;48:307-21.

3. Dehghan N, de Mestral C, McKee MD, et al. Flail Chest injuries: a review of outcomes and treatment practices from the National Trauma Data Bank. J Trauma Acute Care Surg 2014;76;462-8.

4. Majercik S, Sathya V, Griffin O, et al. Surgical stabilization of severe rib fractures decreases incidence of retained hemothorax and empyema. Am J Surg 2015;210:1112-6.

5. Nickerson TP, Thiels CA, Kim BD, et al. Outcomes of complete versus partial stabilization of flail chest. World J Surg 2016;40:236-41.

6. de Campos JRM, White TM. Chest wall stabilization in trauma patients: why, when and how? J Thorac Dis 2018;10:S951-62.

7. Pieracci FM, Rodil M, Stovall RT et al. Surgical stabilization of severe rib fractures. J Trauma Acute Care

Cite this article as: Girotti PNC, Tschann P, Königsrainer I. Prosthetic-free ribs stabilization technique in critical complex chest wall traumas: first results and experiences. J Thorac Dis 2021;13(5):2768-2775. doi: 10.21037/jtd-21-111
Surg 2015;78:883-7.

8. Nirula R, Diaz JJ, Trunkey DD, et al. Rib fracture repair: indications, technical issues and future directions. World $\mathrm{J}$ Surg 2009;33:14-22.

9. Sarani B, Schulte L, Diaz JJ. Pitfalls associated with open reduction and internal fixation of fractured ribs. Injury 2015;46:2335-40.

10. Marasco SF, Sutalo ID, Bui AV. Mode of failure of rib fixation with absorbable plates: a clinical and numerical modeling study. J Trauma 2010;68:1225-33.

11. Leinicke JA, Elmore L, Freeman BD, et al. Operative management of rib fractures in the settling of flail chest: a systematic review and meta-analysis. Ann Surg 2013;258:914-21.

12. Slobogean GP, MacPherson CA, Sun T, et al. Surgical fixation vs nonoperative management of flail chest: a metaanalysis. J Am Coll Surg 2013;216:302-11.e1.

13. Zhang Q, Song L, Ning S, et al. Recent advances in rib fracture fixation. J Thorac Dis 2019;11:S1070-7.

14. Mayberry JC, Terhes JT, Ellis TJ, et al. Absorbable plates for rib fracture repair: preliminary experience. J Trauma 2003;55:835-9.

15. Vu KC, Skourtis ME, Gong X, et al. Reduction of rib fractures with a bioresorbable plating system: preliminary observations. J Trauma 2008;64:1264-9.

16. Senekjian L, Nirula R. Rib fracture fixation, Indication and Outcomes. Crit Care Clin 2017;33:153-65.

17. Bemelman M, Poeze M, Blokhuis TJ, et al. Historic overview of treatment techniques for rib fractures and flail chest. Eur J Trauma Emerg Surg 2016;36:407-15.

18. Shaw RR, Paulson DL, Kee JL. Treatment of Superior Sulcus Tumor by Irradiation Followed by Resection. Ann Surg 1961;154:29-40.

19. Sakakura N, Mizuno T, Arimamura T, et al. Design variations in vertical muscle-sparing thoracotomy. J Thorac Dis 2018;10:5115-9.

20. Abdelsattar ZM, Ishitani MB, Kim BD. Surgical stabilization of rib fractures in a 6-year-old child after blunt trauma. Ann Thorac Surg 2017;104:e439-41. 